\title{
A Scoping Review of Personal Librarian Programs in Academic Libraries
}

\section{Research Findings and Suggested Best Practices}

\section{Presenter:}

James Murphy

Student Learning and Engagement Librarian

james.murphy2@ucalgary.ca

\section{Collaborators:}

Zahra Premji

Research and Learning Librarian, Business

Rhiannon Jones

EMBA/MBA Librarian

Libraries and Cultural Resources, University of Calgary, Canada

Annual Conference on the First-Year Experience

February 15, 2021 


\section{Research Team}

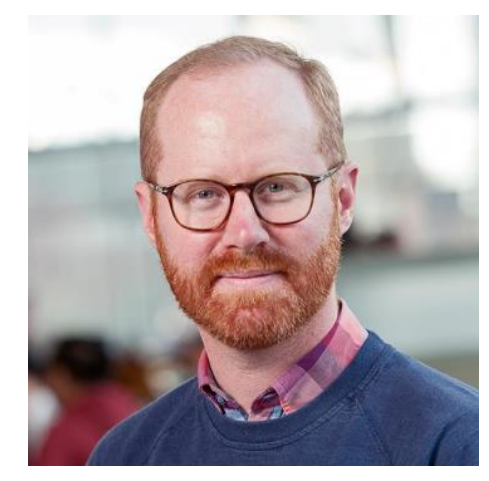

James Murphy Student Learning and Engagement Librarian

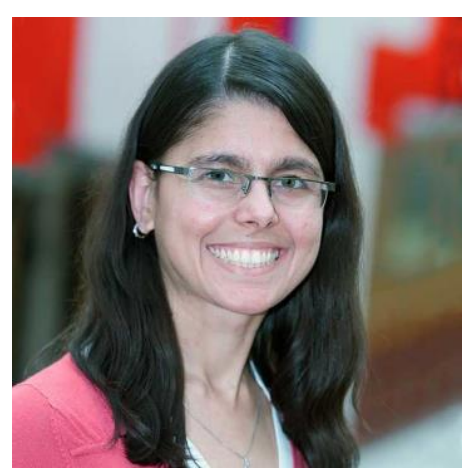

Zahra Premji Research and Learning Librarian, Business

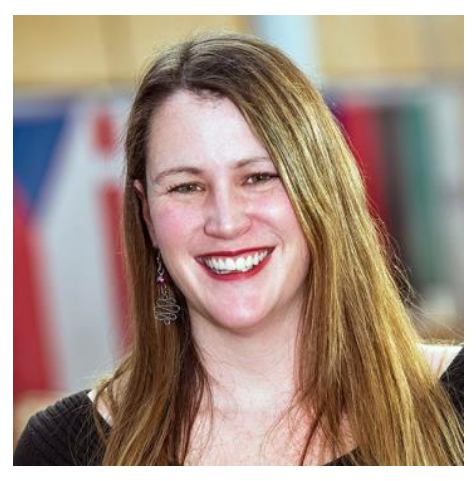

Rhiannon Jones EMBA/MBA

Librarian
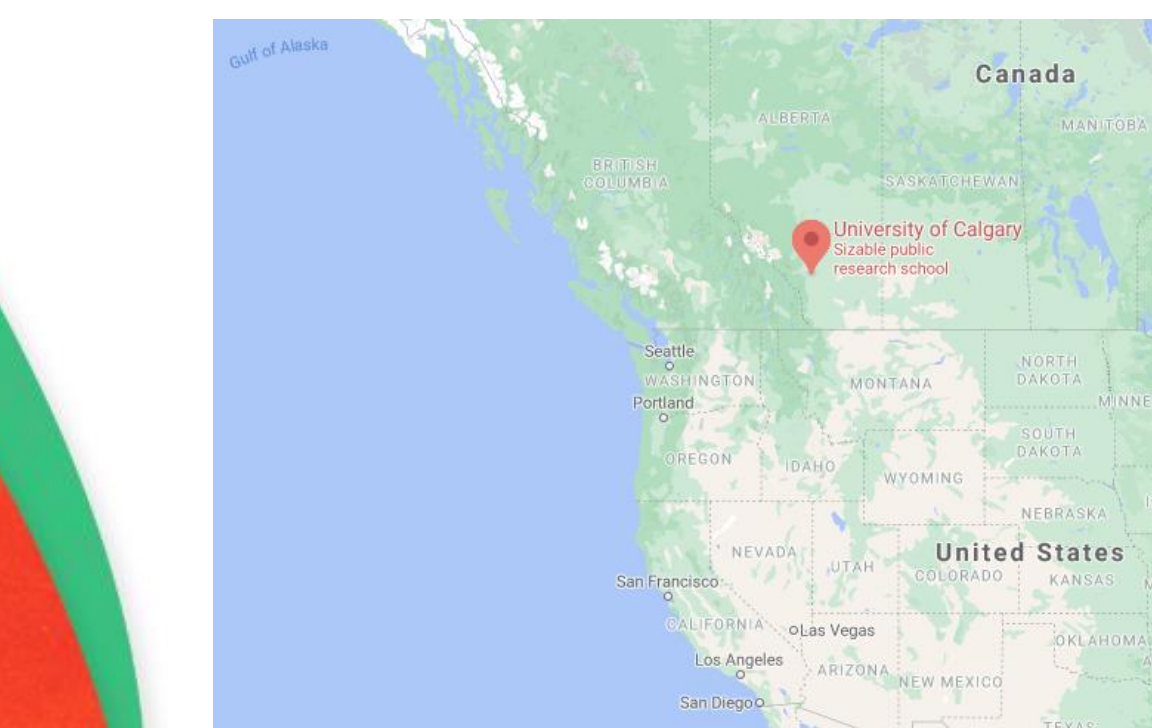


\section{Guiding Questions}

- Interest in developing a personal librarian program

- We wanted to find out:

- Which institutions have offered these?

- What are common program characteristics?

- How have they been assessed?

-What were prominent assessment findings?

- How can we customize the program to our institution?

- This research helped answer these questions, and more! 


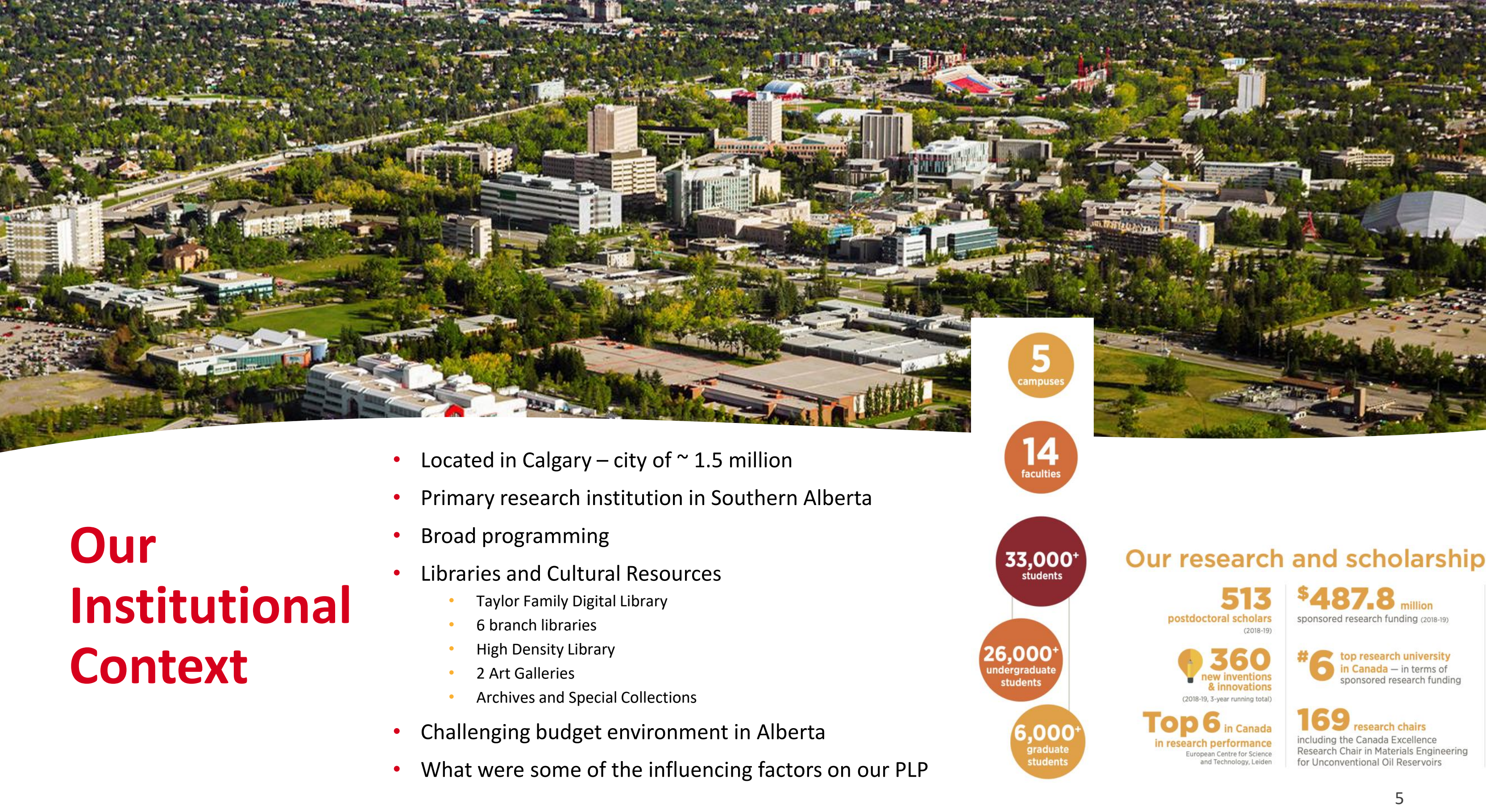




\section{Presentation Overview}

- Guiding Questions

- Our Institutional Context

- Definitions

-What is a personal librarian program?

- Personal librarian vs. Embedded librarian

- Typical program goals

- Scoping Review Methodology

- Databases and resources searched

- Inclusion and exclusion criteria
- Results

- Locations

- Timeline

- Audiences

- Staffing

- Program Components

- Assessment

- Methods used

- Findings

- Suggestions for Program Development

- What did we end up doing?

- $Q$ \& A Discussion 


\section{Definition: Personal Librarian Programs}

PLPs are formalized outreach services that offer targeted communication with the goal of engaging with a defined student user group, outside of the course and subject based embedded services typically focused towards faculty by liaison librarians. 


\section{Embedded versus PLPs}

\section{Embedded Librarians are:}

- Considered active team members of groups (usually course or program based)

- Often liaisons

Personal Librarians are:

- Part of an individual student's experience

- Not necessarily tied to a subject 


\section{Personal Librarian Program Goals}

- What are the typical reasons for starting a PL Program?

- Facilitate personalized connections with new students

- Increase clarity for new students how librarians can help them

- Introduce library related terminology

- Increase student success, research skills, and retention

- Decrease student feelings of isolation in their new environment 


\section{Scoping Review Methodology}
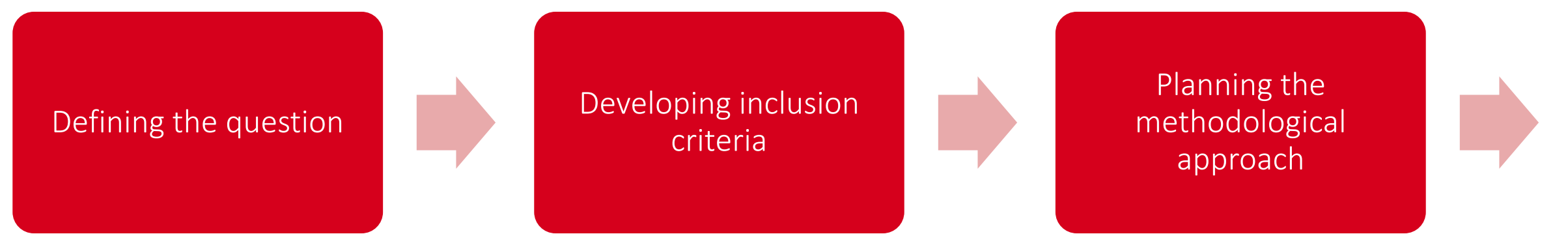

Searching for evidence

Summarising the evidence, making conclusions and noting the implications of the findings
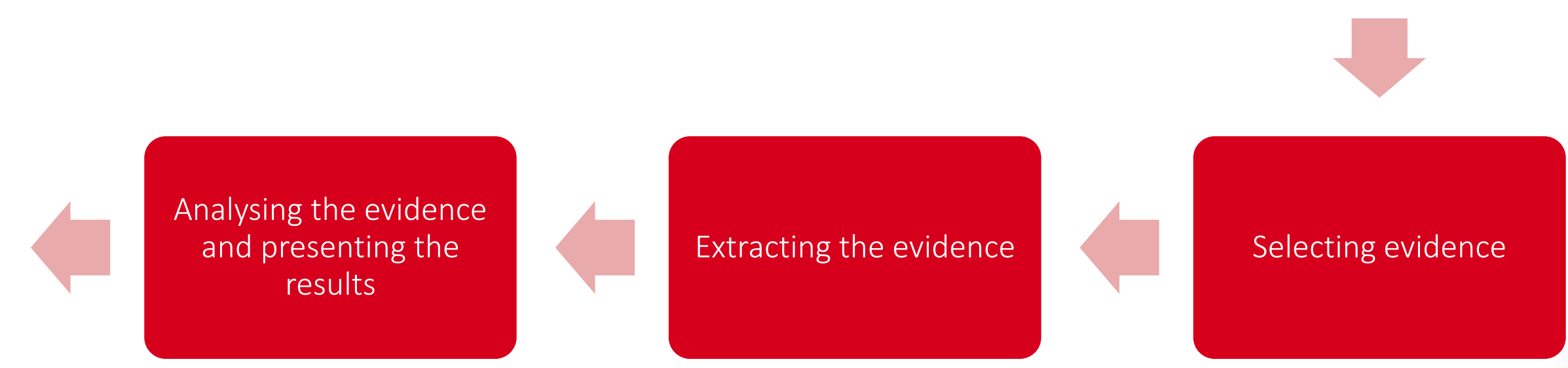

Peters MDJ, Godfrey C, Mclnerney P, Munn Z, Tricco AC, Khalil, H. Chapter 11: Scoping Reviews (2020 version). In: Aromataris E, Munn Z (Editors). JBI Manual for Evidence Synthesis, JBI, 2020. Available from https://synthesismanual.jbi.global. https://doi.org/10.46658/JBIMES-20-12 


\section{Research Question}

- Population

- Students in any educational program; face-to-face, distance or online

- Concept

- Personal librarian programs or personalized outreach programs directly to students

\section{- Context}

- Higher education setting including college, technical schools, universities, etc.

- Both public and private institutions

- Undergraduate and graduate levels.
- Inclusion criteria

- Personal librarian or similar outreach program

- Included evaluation, assessment or reflection

- Published in English

- Published in a scholarly, professional, or trade article, book, book chapter or conference proceeding/poster

- Exclusion criteria

- Embedded programs, not outreach programs

- $\mathrm{K}-12$

- No assessment/evaluation/reflection

- Not in English

- From a newspaper article, newsletter, blog post, etc. 


\section{Methods: Information Sources}

\section{Electronic databases}

Academic Search Complete (EBSCO)

Education Research Complete (EBSCO)

$$
\text { ERIC (EBSCO) }
$$

Library \& Information Science Source (EBSCO)

Library \& Information Science Abstracts

$$
\text { (ProQuest) }
$$

Web of Science Core Collection (SCI-

Expanded, $\mathrm{SSCl}, \mathrm{A} \& \mathrm{HCl}, \mathrm{CPCl}$-Science, $\mathrm{CPCl}$ $\mathrm{SS} \& \mathrm{H}, \mathrm{ESCl})$

\section{Supplementary sources/ strategies}

- Reference lists \& cited bys of all included articles

- Reference lists of all chapters from The Personal Librarian: Enhancing the Student Experience

- Hand searched conferences (recent 3 yrs): ACRL, ALA annual and mid-winter, OLA super conference, Workshop In Library Use, LOEX, IFLA, Personal Librarian \& First Year Experience national conferences, and Annual Conference on The First-Year Experience. 


\section{Methods: Study selection}

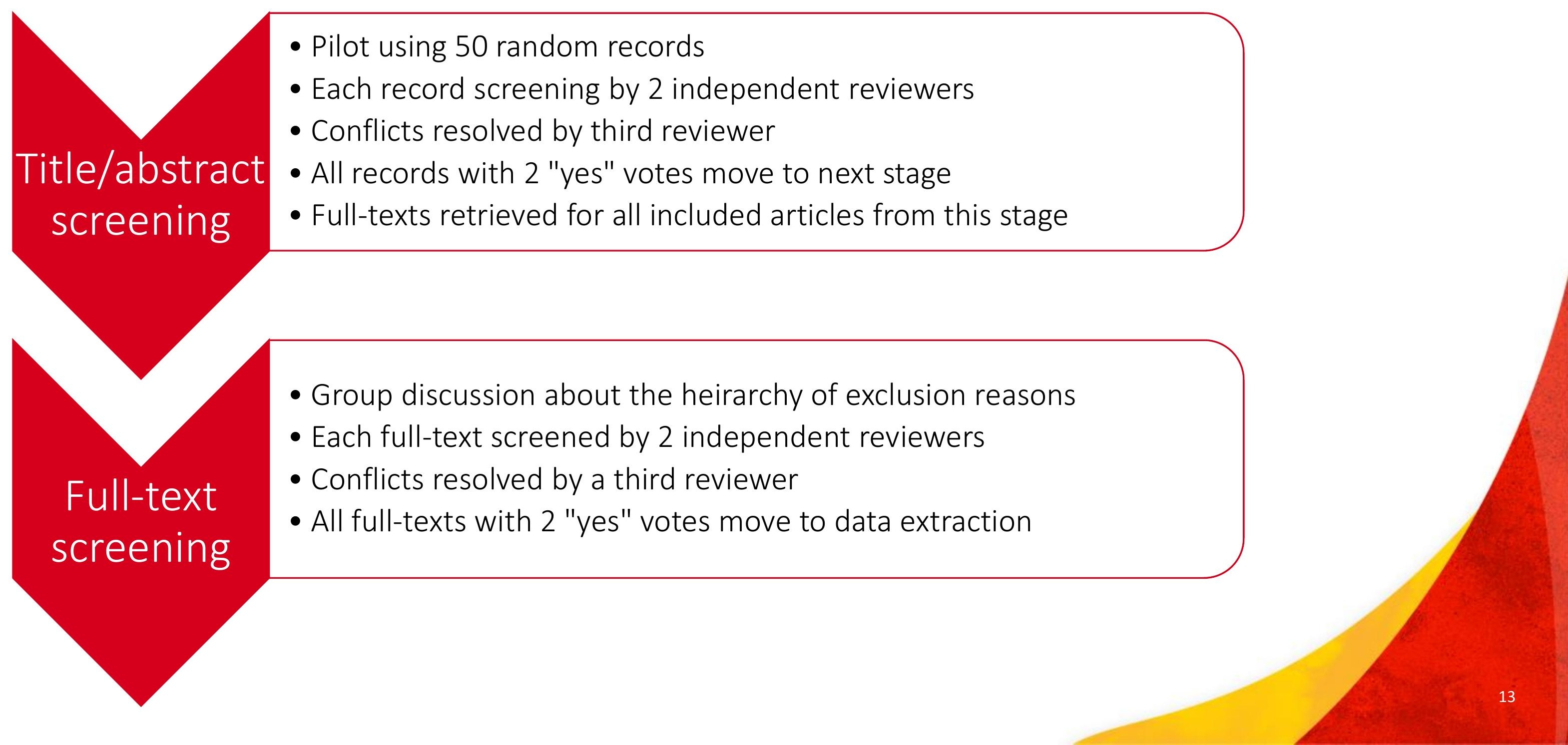




\section{Methods: Data extraction}

\section{Process}

- Data extraction done in duplicate ( 2 independent researchers)

- Conflicts resolved by discussion and consensus as a team

- Used Excel

\section{Data extraction categories}

- Study (Author, year)

- Institution of program

- Country of institution

- Years/dates of program

- Target audience/student group

- Program staffing at outset

- Ratio of librarian/student

- Changes to program staffing at a later date

- Program components

- Evaluation methods \& results

- Additional information 


\section{Results: Study Selection}

Additional records identified through other sources

(n $=1117$

$$
\text { ( } n=16 \text { ) }
$$

Records after duplicates removed ( $n=803$ )

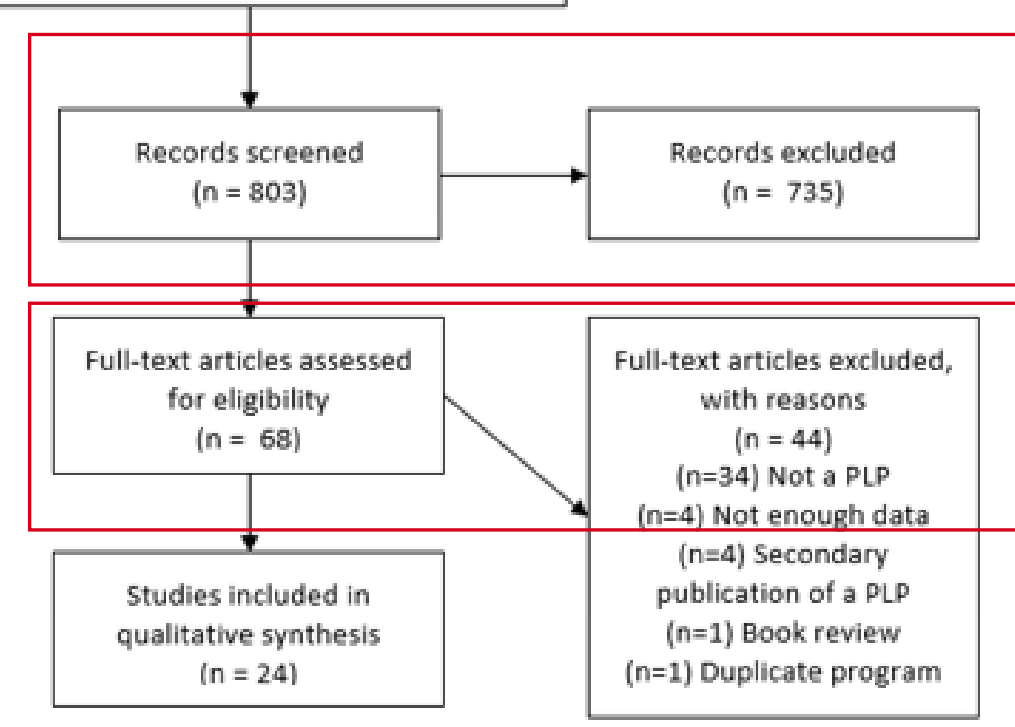

Title/abstract screening stage

Title/abstract screening inter-rater agreement was $94 \%$

\section{Full-text screening stage}

Full-text screening inter-rater agreement was $90 \%$ 


\section{Program Timelines}

- First program created in 1984 (Sam Houston State University)

- Peak of program initiation was 2013-2014

Year of Program Start

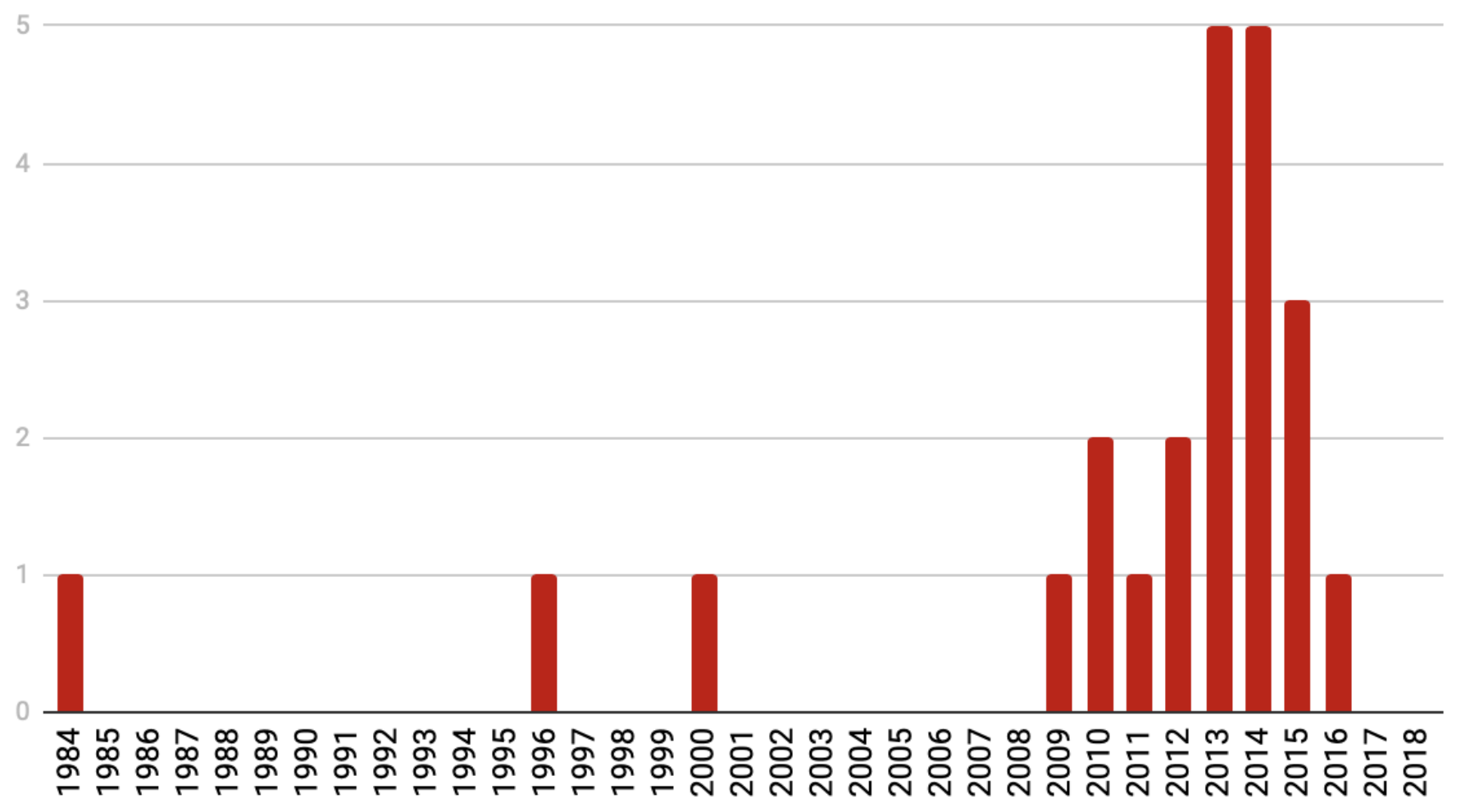




\section{Program Audiences}

- Undergraduates, transfer, and first year graduates most prevalent

- Specialized libraries focused toward their audiences (e.g. Law, MD)

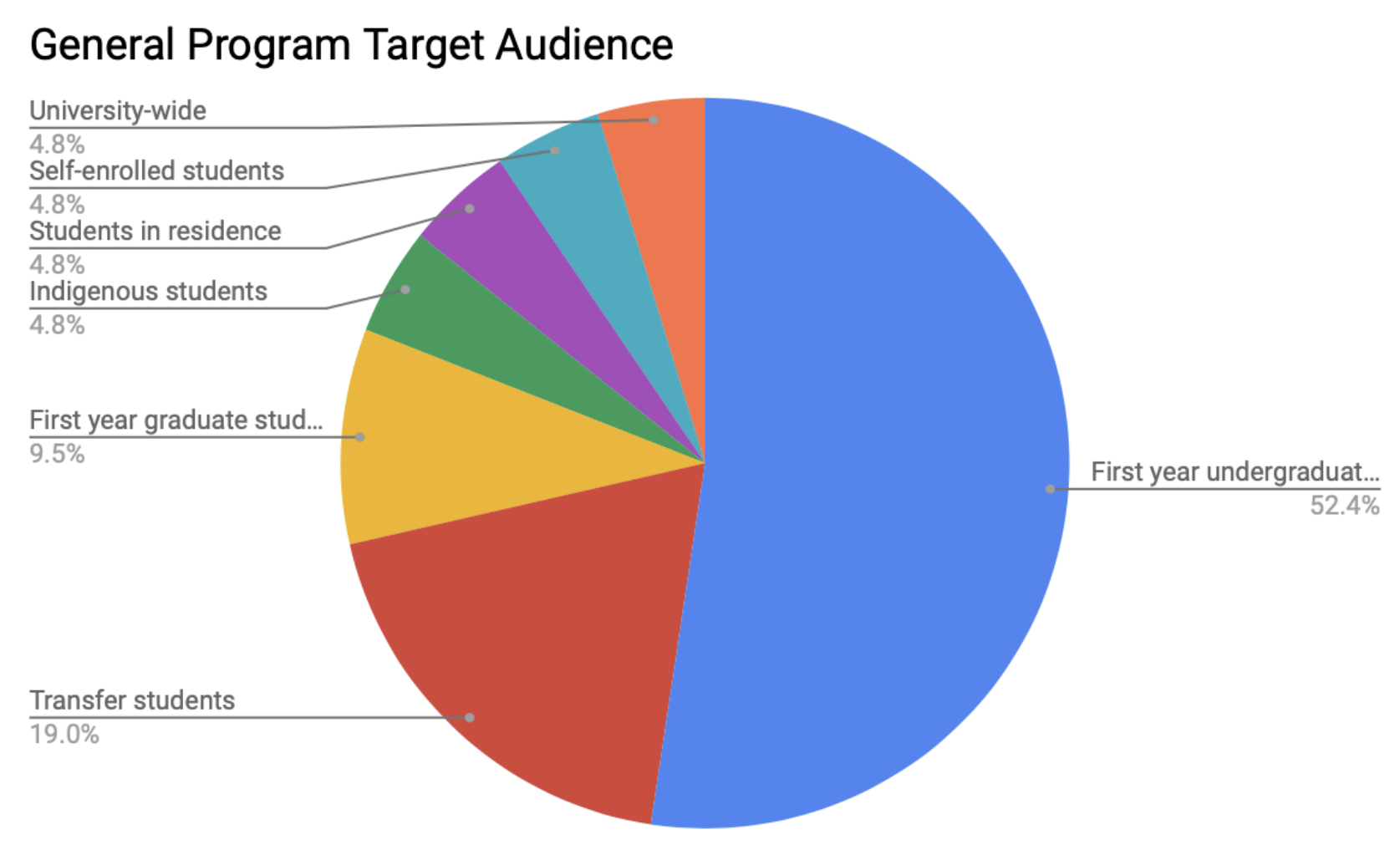




\section{Staffing and Student Ratios}

- Staffing often changed through program years

- Mostly adding more librarians to program staff

Student to Librarian Ratios (if reported)

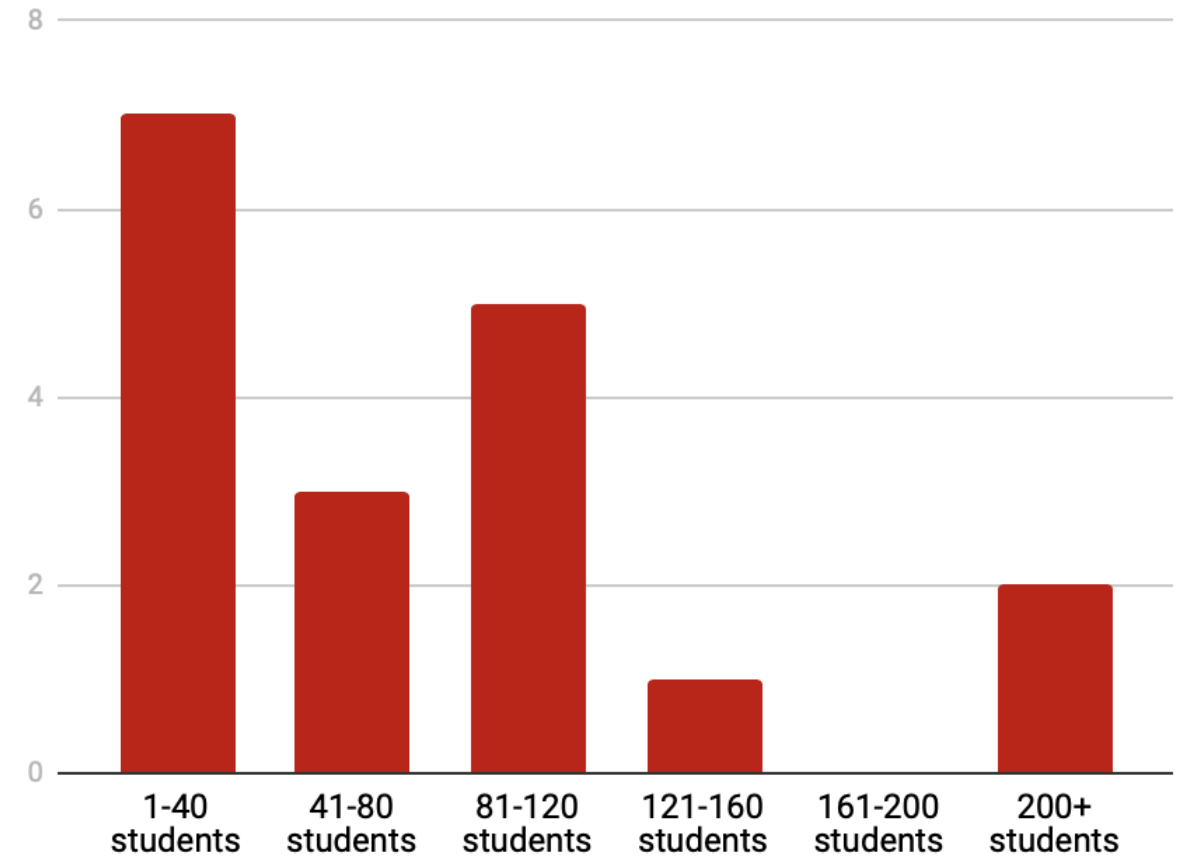

Number of Programs 


\section{Program Components}

- Emails most popular, events second, then mailed letters

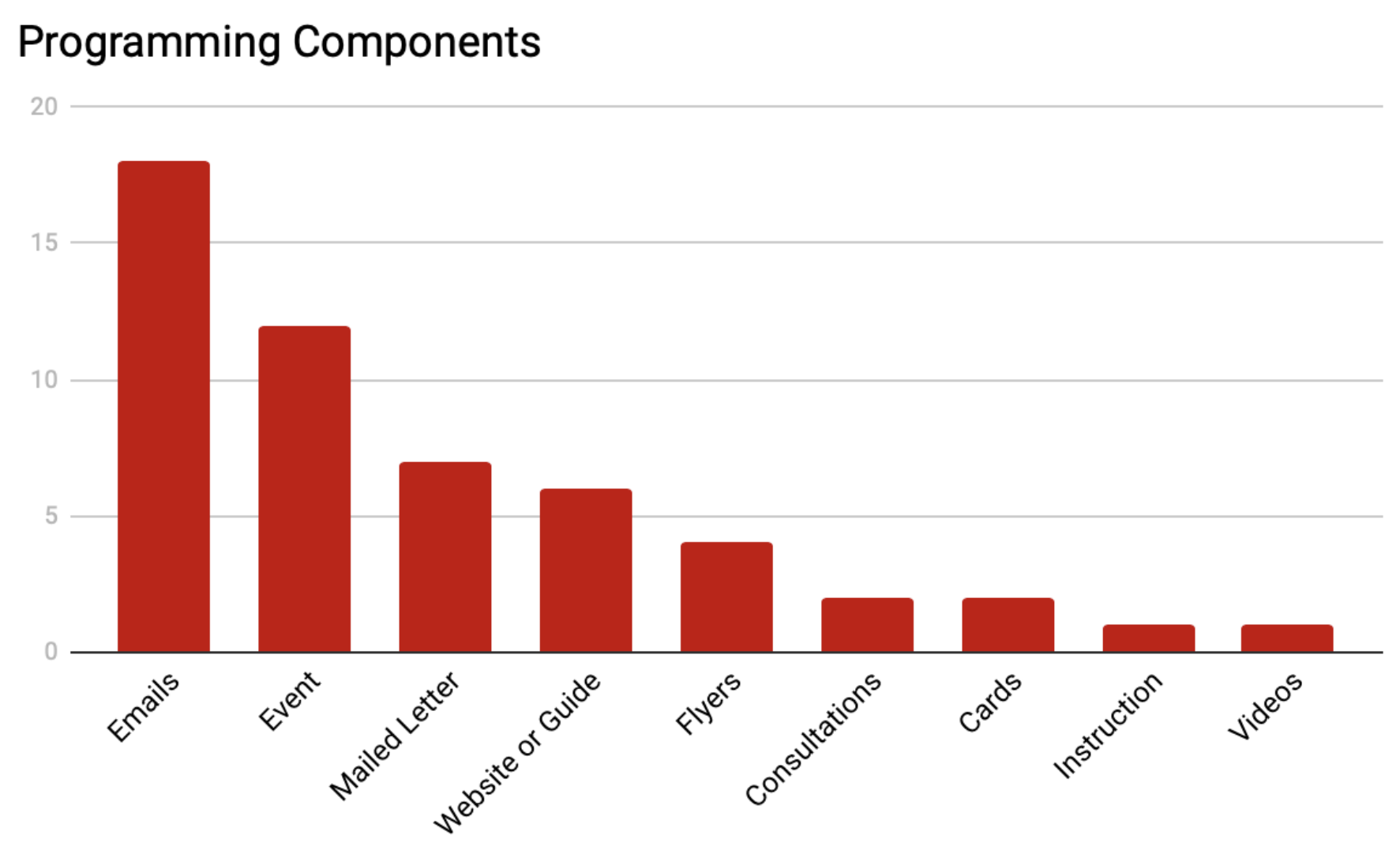




\section{Program Assessment}

- Assessment was an inclusion criteria for the study

- Assessment methods and reporting varied widely among the included studies

- Most common assessment was surveys $(n=16)$, followed by email metrics $(n=8)$

- Anecdotal methods were also utilized

- Assessment was problematic due to inconsistency with reporting, low response rates, and issues with tracking statistics 


\section{Program Assessment: Positive Findings}

- Positive anecdotes

- Increased event attendance

- Positive survey findings

- Students appreciated knowing their library contact

- Increased reference activity 


\section{Program Assessment: Negative Findings}

- Low response rates

- Too many emails

- Emails not being relevant

- Include an opt-out option

- Program success can be difficult to measure 


\section{Questions for Program Development}

-What is the program timeline?

-Who is the target audience?

- Will students be able to opt out?

-Who will staff the program?

-What will the student/staff ratio be?

-What programming will be included?

- What are the program goals?

- How will these goals be assessed? 


\section{Our Personal Librarian Program}

- library.ucalgary.ca/mylibrarian

mýLibrarian

Personalized research and library support for you

\section{What is myLibrarian?}

Librarians provide personalized research and learning help to all University of Calgary students. Whether you need in-depth research help, searching strategies, advice finding goodquality information online, or a friendly expert to chat with, your librarian looks forward to hearing from you!
What can myLibrarian help me with?

- Understanding the scholarship in your field of study

- Suggestions for navigating academic resources on campus

- Searching effectively and efficiently for resources digitally and in print

- Connect you with innovative technology to support your projects

- Finding literature for assignments

- Determining quality of sources

- Managing the scholarly resources you find

- Getting familiar with academic resources including databases

- Focusing a topic you're interested in exploring

- And more!
- Opt-in program

- Curated newsletters

- Builds off liaison program

- New ways of connecting with a librarian (student background, language)

- Active since Sept 2020 


\section{Questions or comments?}

\section{Contact Information}

James Murphy, Student Learning and Engagement Librarian

james.murphy2@ucalgary.ca

Zahra Premji, Research and Learning Librarian, Business

zahra.premii@ucalgary.ca

Rhiannon Jones, EMBA/MBA Librarian

rhiannon.jones@haskayne.ucalgary.ca

Libraries and Cultural Resources, University of Calgary, Canada 